of Cambridge) and G. Wilkinson (Imperial College, London) are among eleven academics who point out that the rash of new chemistry journals appearing subsist on high subscription rates rather than publication charges from the authors. They believe that some of the new journals, with a vested interest in building up volume to maintain themselves, have refereeing standards which are lax, to say the least (a certain journal in the field of inorganic and nuclear chemistry has "minimal refereeing standards", and contains "stuff which ought never to see the light of day", says Professor Wilkinson).

The chemists see over-specialisation encouraging the proliferation of journals and being in turn encouraged by them at a time when there should be more communication between scientists working in different areas. They urge, as a quick way of getting the message over to publishers, that scientists should ask their libraries to think twice about subscribing to new commercial journals, and themselves refrain from publishing in them. Somewhat idealistically, they talk of the need for an international agency to examine the founding of new journals, and further suggest that national chemical societies (though they be far from perfect and their track records not always shining bright) should set up "an impartial mechanism for evaluating the need for a new journal and require that criteria for assuring the level of quality is met". This committee's concerns would include "a set of criteria for refereeing practice, statistics about rejection rates, criteria for terminating a journal, restrictions on language of national origin of work, page charges, and so on."

The Chemical Society's Director of Publications, Dr L. C. Cross, confirms the complaints of the group and sums up the overall problem of over-specialisation and the haphazard division of new knowledge into packages of narrow interest in the following terms: "This has merely resulted in ever multiplying costs to the consumer and greater profits to the producer. Such results are inevitable because the package is not being altered fundamentally, only the label is being changed, with results that any housewife would predict".

Another group of scientific authors and editors, including Dr Monty Finniston (Materials Science), Professor J. P. Hartnett (International Journal of Heat and Mass Transfer) Professor N. Kurti (International Monographs of Solid State Physics), and Sir Harold Thompson (Spectrochimica Acta) lamented over soaring prices in a letter to Sir Walter Coutts, chairman of their publishers, Pergamon Press Ltd. They also proposed a remedy which, a sceptic might remark, was not guaranteed ab- solutely to reverse the trend.

"We are alarmed" (they said) "at the regular annual exorbitant price increases on books and journals, not only by Pergamon but also by other publishers. These augmentations have practically eliminated purchases of publications by private individuals. Libraries, with fixed or reduced budgets, are facing impossible choices between urgently needed publications. Also we deplore the fact that resulting from these price increases students are buying fewer and fewer books for their personal use. Here we need the kind of imaginative leadership that Robert Maxwell can provide in order to reverse disastrous pricing trends in the publishing industry and to help meet these other difficulties",

On the strength of this recommendation (and of rival claims for the merits of a counter proposition) $\mathrm{Mr}$ Maxwell was asked by Nature whether Pergamon was specially culpable over the issues at stake and what, if anything, he proposed in order to make life more bcarable for subscribers.

In the first place, says $\mathrm{Mr}$ Maxwell, Pergamon's total of 142 scientific journals represents a growth of less than $5 \%$ over the past two years. "There is a growing number of people doing research in a growing number of subjects and because of the pressure on existing publication machinery it is inevitable that new journals emerge to meet these new demands. These chaps have a point about proliferation but in no case do we, the publishers, initiate a new journal; not a single one. A group of scientists will write in and say they feel there is a need for a journal in a certain area, so we talk about it and carry out a detailed, world-wide survey, and if there is a genuine need then we go on from there. But really, the actual proliferation has slowed down immensely".

Naturally enough, Mr Maxwell defends the standards of the referees used by Pergamon. Like the editors and editorial boards of his journals, the refereeing is "of the highest standard". Sometimes, he adds, a paper rejected by a Pergamon publication will turn up in the journal of a learned society, although this is not to say that in a vast output of 20,000 papers a year there is not "an occasional slip-up if a referee has not been as careful as he ought to have been".

As for the cash angle, Mr Maxwell is in scientific publishing because he likes to be of some help to science and, not having been to university, he does

\section{Dispute halts abstracts scheme}

\section{Colin Norman, Washington}

A Dispute between the American Institute of Physics (AIP) and the London-based Institution of Flectrical Engineers (IEE), has brought to a temporary halt an attempt to rationalise the production and marketing of physies abstracts. It seems that the IEE, for financial reasons, has abrogated an agreement worked out between the two organisations last summer, and as a consequence, the AIP has terminated the marketing of IEE information products in the United States-a service which the American society has been performing for the past five years. The disagreement came to light recently when the executive directors of the societics traded public statements on the matter, but both have expressed the hope that a new arrangement can still be worked out.

The cost of producing abstracts of physical articles has shot up in the past few years, with the result that Physics Abstracts, the key IEE service, has increased in price from $\$ 12$ in 1967 to $\$ 380$ in 1974 . It is thus circulated chiefly to institutions rather than to individuals. The
AIP abstracting services, however, are geared at least partly to the needs of individual subseribers, and in that respect the two services are complementary and compatible. Moreover, since more than $25 \%$ of the IEE abstracts are taken from papers published in the primary journals of the AIP, there is clearly considerable scope for cooperation in the production of the abstracts.

Against that background, officials of the two societies worked out an agreement in June last year under which the AIP would supply the IEE with computer-readable abstracts of articles published in AIP journals. The agreement would also have given the AIP considerable influence over the content and design of IEE abstracts, and the British society would have reimbursed AIP for the service. The arrangement would have permitted multiple use of each computer tape, thereby cutting down production time and costs of abstract journals. IEE officials later felt that they were getting a raw financial deal, and reneged on their commitments, whereupon the AIP discontinued marketing IEE products. IEE abstracts are now marketed in the United States by the Institution of Electrical and Electronics Engineers (IEEE). 